\title{
A High Power Thyristor Rectifier with Low Harmonics and High Power Factor
}

\author{
Ozgun Girgin (Corresponding author) \\ Department of Electrical Engineering, Yildiz Technical University, Istanbul/Turkey \\ E-mail: ogirgin@yildiz.edu.tr \\ Halit Zengince \\ Esis Power Inc., Tuzla, Istanbul/Turkey \\ E-mail: halit.zengince@esis.com.tr \\ Ahmet Faruk Bakan \\ Department of Electrical Engineering, Yildiz Technical University, Istanbul/Turkey \\ E-mail: fbakan@yildiz.edu.tr
}

The research is financed by the Republic of Turkey Ministry of Industry and Technology Project No. 0791.STZ.2011-1

\begin{abstract}
Three-phase thyristor rectifiers are widely used in industrial applications. The harmonic content of the input current in this converter is very high. Decreasing total harmonic distortion of the input current is very important to comply with IEEE-519 standards and IEC- 61000-3-2, and for energy quality issues; therefore, a harmonic reduction technique is needed to solve the problem. This paper presents an adaptive filter for high power thyristor rectifiers. The proposed filter can provide compensation for reactive power in a wide range from $25 \%$ to $100 \%$ load with low input current harmonics. The most suitable design has been selected in terms of performance, reliability, ease of control and low cost. Simulation for the proposed harmonic reduction scheme has been performed by using the PSIM simulation program.
\end{abstract}

Keywords: current harmonics, energy quality, harmonic reduction, power factor correction, total harmonic distortion, thyristor rectifiers

DOI: $10.7176 / \mathrm{JSTR} / 5-2-14$

\section{Introduction}

Three-phase controlled rectifiers, the most commonly used converter type among power electronics converters, are widely used for DC power supplies, battery chargers, motor control, electrochemical process, dc arc furnaces, and many other applications (A. M. Trzynadlowski,2016). A stationary battery charger is used in utility, switchgear, and other industrial environments however it causes the variation of voltage and current over a wide range. In these applications battery voltages and currents vary between $110 \mathrm{~V}-220 \mathrm{~V}$ and 40A-400A, respectively. To provide continuous DC energy, batteries are connected to the output of the controlled rectifiers. These rectifiers are also called battery chargers. However, one of the disadvantages of the rectifiers is that draw huge reactive power from the mains that cause power losses. Limitation of power factor and harmonic content is extremely necessary in order to reduce the losses in the system.

In the controlled rectifier, thyristors are preferred as semiconductor power switches. Thyristor has the highest current and voltage capacity among power semiconductor switches. In these converters, thyristors are preferred to the other semiconductor switches especially at high power levels due to their high reliability and relatively low costs. In a three-phase controlled rectifier, the number of pulses in the output voltage depends on the number of thyristors. six-pulse rectifier, which includes 6 thyristors, is widely used due to its simple and reliable structure. In this converter a three-phase transformer is used

119 | P a g e

www.iiste.org 
for isolation and voltage transformation. In three-phase rectifiers, reactive power increases with delay angle. Besides, the total harmonic distortion of the input current (THDi) is very high. Especially, in the future, the energy quality will gain great importance in terms of compliance with IEEE international standards in the industry. Therefore, the need for high power rectifiers with high power factor and low harmonics will increase. Decreasing THDi value is very important to comply with IEEE-519 standards and IEC-61000-3-2, and for energy quality issues (IEEE Standard 519, 1992, Alexa, D. et. al. 2004). THDi value is approximately $32 \%$ in six-pulse rectifiers. In order to decrease the THDi value, many techniques are proposed in the literature (Hacer Ucgun \& Yasemin Onal, 2018, B. Sanzhong \& M. L. Srdjan, 2013, S. Srdic and M. Nedeljkovic, 2011).

Twelve-pulse rectifiers are used to decrease THDi value and output voltage ripple. In these rectifiers, $30^{\circ}$ phase shifted three-phase voltages, and twelve thyristors are used. In a twelve-pulse rectifier, THDi value is approximately $15 \%$. To decrease the THDi to lower value it is required to increase the phase voltages and the number of thyristors. This method is preferred to a certain extent due to the difficulties in multiphase transformer production, and the high number of thyristors which increase the complexity and cost of the system.

Another method to decrease THDi value in controlled rectifiers is using passive filters. However, passive filters cannot alone provide adequate performance at variable load conditions. Therefore, to improve the energy quality, and to meet variable reactive power demand, the use of active power filter (APF) has drawn much attention. Originally, using a stand-alone APF prefers for mitigating the harmonics rather than correction of the power factor. APFs can limit the benefits resulting from its harmonic reduction ability because of both its poor power factor compensation capability and the cost.

This paper presents a cost-effective solution in order to overcome the aforementioned limitations. In this paper, first six-pulse and multipulse thyristor rectifiers have been analyzed theoretically and simulated. After that a low harmonic and high power factor 122V/400A rectifier has been developed. The developed rectifier is used for battery charging purposes, but also it could be adapted to the applications such as electroplating rectifiers, dc power source etc. by software modification. In the developed rectifier, THDi value is lower than $9 \%$, and the power factor value is higher than 0,95 in wide range load conditions. Thus, an adaptive filter which provides a good power factor and low harmonic contents in a high power controlled rectifier is obtained.

\section{Industrial Rectifiers and Harmonic Standards}

The use of thyristor rectifiers is increasing day by day when controlled DC voltage is needed. However, with the widespread use of three-phase rectifiers, harmonic pollution in the energy system is increasing steadily. For this reason, the harmonic pollution of electric energy is limited for increasing of power quality. Limitation of harmonic contents is extremely necessary in order to reduce the losses in the system, to use the elements in the system with full capacity and to eliminate the stresses and failures caused by the harmonics. According to international standards, harmonic content is limited at different power levels and application areas. In the future, the quality of the energy will gain great importance in terms of standards for the industry. Therefore, the need for high power rectifiers with low harmonics and high power factor will increase. Besides, the serious problem of industrial rectifiers, known as six pulse rectifiers, include large harmonic contents in their input currents. The line current of a controlled converter and its fast Fourier transform (FFT) components are shown in Fig. 1b. It is clear from this waveform that this converter generates high harmonics in the line currents which distort the voltage at the point of common coupling in the power system.

Rectifiers generate the order of, $n \times m \pm 1$, the characteristic harmonics. Here, $n$ is an integer and $m$ is the pulse number. For example, a six-pulse rectifier generates 5, 7, 11, 13, 17, 19th... harmonics. These aspects adversely affect both the power factor and power quality. Low power factor causes high current. When the firing angle $\alpha=0^{\circ}$, the total harmonic distortion of the input current (THDi) is approximately $31 \%$.

$$
\begin{aligned}
& \mathrm{h}=(6 \mathrm{n} \pm 1) \text { th }(\mathrm{n}=1,2,3 \ldots) \\
& \mathrm{I}_{\mathrm{sh}}=\mathrm{I}_{\mathrm{s} 1} / \mathrm{h}
\end{aligned}
$$




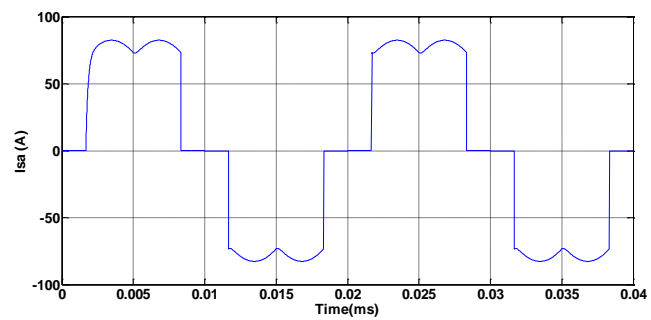

a)

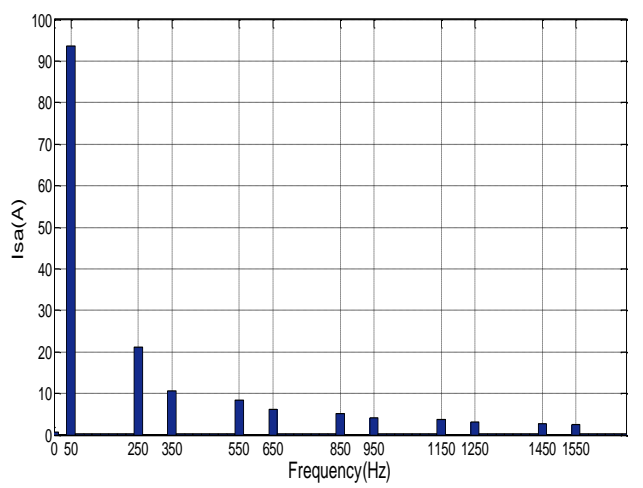

b)

Figure $1 \mathrm{a}$ ) Input current $\left(\mathrm{I}_{\mathrm{sa}}\right)$ waveform of thyristor rectifier when the firing angle $\alpha=0^{\circ}$

b) Harmonic contents in the input current $\left(\mathrm{I}_{\mathrm{sa}}\right)$

Equations (1) and (2) are shown as means for determining the order and magnitude of harmonic currents. From Eq. 2, it can be understood as the division of the fundamental current and the harmonic number will result in the magnitudes of the harmonic currents. (e.g., the magnitude of the 5 th harmonics is about $1 / 5$ of the fundamental current). The Fourier Transform of the waveform is calculated to derive harmonic components. The Fourier component for the 6-pulse rectifier can be expressed as:

$$
\begin{aligned}
& \mathrm{i}_{\mathrm{sa}}(\omega \mathrm{t})=\sqrt{2} \mathrm{I}_{\mathrm{s} 1} \times \sin (\omega \mathrm{t}-\alpha)-\sqrt{2} \mathrm{I}_{\mathrm{s} 5} \times \sin [5(\omega \mathrm{t}-\alpha)]-\sqrt{2} I_{s 7} \cdot \sin [7(\omega t-\alpha)]+\sqrt{2} I_{s 11} \cdot \sin [11(\omega t-\alpha)] \\
& +\sqrt{2} I_{S 13} \cdot \sin [13(\omega t-\alpha)]-\sqrt{2} I_{S 17} \cdot \sin [17(\omega t-\alpha)]-\sqrt{2} I_{S 19} \cdot \sin [19(\omega t-\alpha)] \ldots
\end{aligned}
$$

The result of using Eq. 3 that 6-pulse thyristor rectifiers include $5_{\text {th }}$ and $7_{\text {th }}$ harmonic components in the input current. This equation consists only of odd harmonics except for the triplen harmonics. Actually, when the firing angle $\alpha$ is zero, the input current waveform for controlled rectifier becomes an uncontrolled rectifier. Also, its PF value is higher than 0.95 in this operating mode. As the angle of the harmonic components of the rectifiers increases, the deterioration of the current waveform increases. Hence, the input current harmonics cannot comply with international standards and recommendations, for example, IEEE-519. For this reason, special attention has to be paid to harmonics. The recommended current distortion limits are given Table 1 . Where, $\mathrm{I}_{\mathrm{SC}}$, and $\mathrm{I}_{\mathrm{L}}$, are maximum short-circuit current and maximum demand load current at the point of common coupling, respectively. 
Table 1 IEEE 529 Harmonic Limits

\begin{tabular}{|c|c|c|c|c|c|c|}
\hline ISC/IL & $\mathrm{h}<11$ & $11<\mathrm{h}<17$ & $17<\mathrm{h}<23$ & $23<\mathrm{h}<35$ & $35<\mathrm{h}$ & $\begin{array}{c}\text { THDi } \\
(\%)\end{array}$ \\
\hline$<20$ & 4.0 & 2.0 & 1.5 & 0.6 & 0.3 & 5.0 \\
\hline $20-50$ & 7.0 & 3.5 & 2.5 & 1.0 & 0.5 & 8.0 \\
\hline $\begin{array}{c}50- \\
100\end{array}$ & 10.0 & 4.5 & 4.0 & 1.5 & 0.7 & 12.0 \\
\hline $100-$ & 12.0 & 5.5 & 5.0 & 2.0 & 1.0 & 15.0 \\
\hline 1000 & & & & & & \\
\hline$>1000$ & 15.0 & 7.0 & 6.0 & 2.5 & 1.4 & 20.0 \\
\hline
\end{tabular}

In the effective solution to obtain a dc power without harmonic pollution from the utility, passive filters are used. Filters can be used separately for each harmonic. In order to reduce the number of filter elements, a single filter is used, especially for high-value harmonics. For example, to suppress the 17th and 19th harmonics, a single filter is used for the 17th and 19th harmonics by matching the center frequency of the filter to the 18th harmonic. If a rectifier design is used to increase the number of pulses to comply with the standards, it is observed that the number of pulses is 48 and over. Therefore, the current becomes more sinusoidal waveform as the number of pulses increases and this decreases THDi value. However, this design is both costly and complex.

\section{Multipulse Rectifiers}

Among various harmonic distortion mitigation techniques, the pulse multiplication is examined in this section. Multipulse rectifiers can provide the above mentioned international standards without a filter. There is information in the literature that at least 48 pulse rectifiers could meet the IEEE-519 standards. Especially, multipulse rectifiers are preferred to reach high power levels. It is important to reduce the current harmonics generated on the ac side in high power applications. An m-pulse converter requires $\mathrm{m}$ $/ 6=\mathrm{N}$ rectifiers. Here, $\mathrm{m}$ is the pulse number and $\mathrm{N}$ is the total number of rectifiers. In multipulse rectifier systems are phase shifted exactly 60 / $\mathrm{N}$ degrees from each other. To eliminate harmonics, multipulse thyristor rectifiers using phase-shifting transformers are developed. The use of phase shifting transformer provides some of lower order harmonic components generated by the six pulse rectifiers are canceled. For example, two rectifiers that are phase shifted $30^{\circ}$ result in 12 -pulse and the current of the sampled rectifier is closer to sinusoidal form than single six-pulse rectifier. Each 6-pulse rectifier must have the same transformer ratios. Besides, each rectifier must have controlled at the same delay angle and share the dc load current equally. If a multipulse rectifier system does not have one of that conditions, even order harmonics occur. Twelve pulse rectifiers' Fourier Transform components could be expressed as:

$$
\begin{aligned}
& i_{s a 1}(\omega t)=\frac{2 \sqrt{3}}{2 a \pi} I_{d} \cdot\left(\cos \omega t-\frac{1}{5} \cos 5 \omega t+\frac{1}{7} \cos 7 \omega t-\frac{1}{11} \cos 11 \omega t+\frac{1}{13} \cos 13 \omega t \ldots\right) \\
& i_{s a 2}(\omega t)=\frac{2 \sqrt{3}}{2 a \pi} I_{d} \cdot\left(\cos \omega t+\frac{1}{5} \cos 5 \omega t-\frac{1}{7} \cos 7 \omega t-\frac{1}{11} \cos 11 \omega t+\frac{1}{13} \cos 13 \omega t \ldots\right) \\
& i_{s a}=i_{s a 1}+i_{s a 2}
\end{aligned}
$$


$i_{s a}(\omega t)=\frac{2 \sqrt{3}}{2 a \pi} I_{d} \cdot\left(\cos \omega t-\frac{1}{11} \cos 11 \omega t+\frac{1}{13} \cos 13 \omega t \ldots\right)$

From the Eq. 3, when it comes to 12-pulse rectifiers, Eq. 7 can be obtained. It can be seen that the 5 th and 7 th harmonics are eliminated in Eq. 6. This enables to offset the harmonic components such as 5th and 7 th produced, but the $12 \mathrm{~m} \pm 1$ th harmonics are still in the input current. Harmonics can be analyzed with the process of calculating the magnitudes and high order components of the periodic waveform in Eq. 7.

As shown in Table 2, in a 6-pulse rectifier, there are low harmonics of 5, 7, 11, 13 etc. which have very high values. The THDi is $31.1 \%$ and also this value is significantly higher than IEEE limits. The value of harmonics 11th and 13th in the 12- pulse rectifier is quite high. The THDi of a twelve-pulse rectifier is approximately half of 6-pulse rectifier, but the mentioned limit is still not provided. To achieve the THDi value under the IEEE limits, multipulse multiplication is used and it can be seen that 48-pulse rectifier ensure successfully proposed technique. It is seen that there is not required to use any extra measures in the 48-pulse rectifier.

Table 2 Harmonic Contents of Multipulse Rectifiers

\begin{tabular}{|l|l|l|l|l|l|}
\hline $\begin{array}{l}\text { Pulse } \\
\text { Number } \\
(\mathbf{m})\end{array}$ & $\mathbf{6}$ & $\mathbf{1 2}$ & $\mathbf{2 4}$ & $\mathbf{3 6}$ & $\mathbf{4 8}$ \\
\hline THDi (\%) & 31.078 & 15.213 & 7.764 & 5.249 & 4.005 \\
\hline $\mathbf{I}_{\mathbf{5}}(\mathrm{A})$ & 22.127 & 0 & 0.196 & 0.189 & 0.302 \\
\hline $\mathbf{I}_{\mathbf{7}}(\mathrm{A})$ & 15.851 & 0 & 0 & 0 & 0 \\
\hline $\mathbf{I}_{11}(\mathrm{~A})$ & 10.043 & 10.007 & 1.340 & 1.080 & 0.964 \\
\hline $\mathbf{I}_{13}(\mathrm{~A})$ & 8.547 & 8.541 & 1.167 & 0.851 & 0.803 \\
\hline $\mathbf{I}_{17}(\mathrm{~A})$ & 6.489 & 0 & 0 & 0 & 0 \\
\hline $\mathbf{I}_{19}(\mathrm{~A})$ & 5.856 & 0 & 0 & 0 & 0 \\
\hline $\mathbf{I}_{\mathbf{2 3}}(\mathrm{A})$ & 4.789 & 4.764 & 4.885 & 0.461 & 0.287 \\
\hline $\mathbf{I}_{\mathbf{2 5}}(\mathrm{A})$ & 4.457 & 4.460 & 4.582 & 0.497 & 0.332 \\
\hline $\mathbf{I}_{\mathbf{2 9}}(\mathrm{A})$ & 3.792 & 0 & 0 & 0 & 0 \\
\hline $\mathbf{I}_{\mathbf{3 1}}(\mathrm{A})$ & 3.599 & 0 & 0 & 0 & 0 \\
\hline $\mathbf{I}_{35}(\mathrm{~A})$ & 3.137 & 3.116 & 0.409 & 3.189 & 0.235 \\
\hline $\mathbf{I}_{\mathbf{3 7}}(\mathrm{A})$ & 3.020 & 3.026 & 0.422 & 3.105 & 0.359 \\
\hline
\end{tabular}

The changes in the input current THDi values are examined based on the delay angle in Table 3 . As the delay angle is increased, rectifier shows more distortion characteristics. Also, another result can be seen that the THD value is reduced by increasing the number of pulses. However, the number of elements and control complexity are increasing. The reactive power of the required passive filter is high for suppressing these harmonics. 
Table 3 Performance Comparison of Multipulse Rectifier

\begin{tabular}{|l|l|l|l|}
\hline \multirow{2}{*}{$\begin{array}{l}\text { Pulse } \\
\text { Number(m) }\end{array}$} & \multicolumn{3}{|c|}{ Total Harmonic Distortion } \\
\cline { 2 - 4 } & \multicolumn{3}{|l|}{ Firing angle of devices in rectifiers } \\
\cline { 2 - 4 } & $\boldsymbol{\alpha}=\mathbf{0}^{\circ}$ & \multicolumn{1}{|l|}{$\mathbf{3 0}^{\circ}$} & $\mathbf{\alpha}^{\circ} \mathbf{6 0}^{\circ}$ \\
\hline 6-pulse & 31.07 & 36.75 & 41.57 \\
\hline 12-pulse & 15.21 & 12.90 & 16.48 \\
\hline 18-pulse & 10.21 & 10.91 & 11.40 \\
\hline 24-pulse & 7.76 & 7.56 & 9.33 \\
\hline 36-pulse & 5.24 & 7.02 & 8.34 \\
\hline 48-pulse & 4.00 & 5.65 & 7.56 \\
\hline
\end{tabular}

In the choice of the multi-pulse rectifier with the filter elements, total cost and complexity criteria come out. Resonance between the network and filter elements must be prevented and reactive power compensation should be provided throughout the entire operating range. The difficulty of performing the multi-pulse rectifier (number of thyristors, power density, the complexity of control circuit etc.) should also be evaluated in terms of reliability. According to all these conditions, the proposed structure that is designed and explained below.

\section{Simulation Results}

Fig. 2 shows that a thyristor rectifier structure with low harmonics and high power factor. The purpose of the proposed system is that the input current THDi is less than the limits, the input power factor is between 0.95 and 0.99 . Simulation results have proved the effectiveness of the proposed three-phase lowharmonic rectifier. This approach contains D-D and D-Y transformers that provide phase shifting. These transformers are selected for the twelve-pulse rectifier. It can be seen that first six-pulse rectifier is fed from D-D transformer, while the other rectifier is fed from D-Y transformer to produce the 12-pulse rectifier effect on dc output in terms of phase shift.

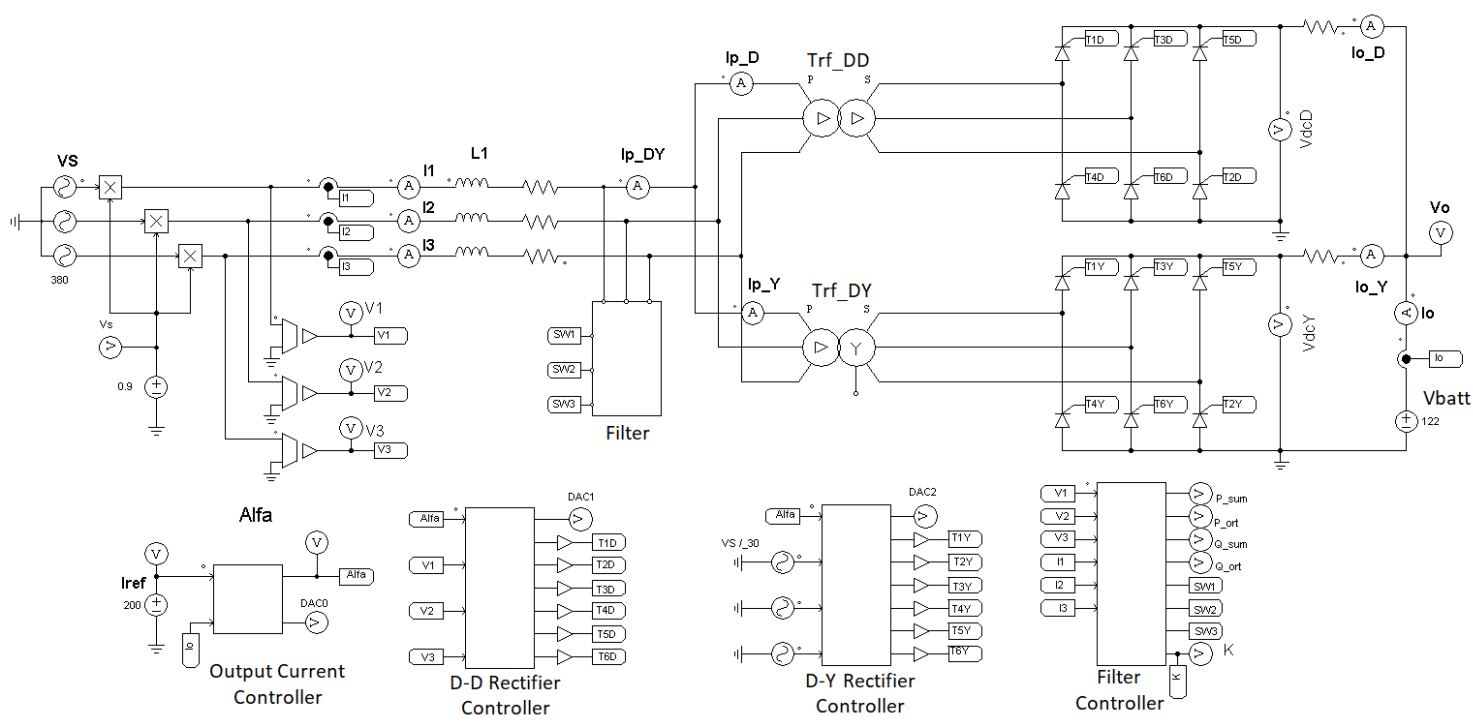

Figure 2 Proposed Approach 
To analyze the performance of proposed rectifier, detailed simulations are carried out on the PSIM and MATLAB computer programs. Simulation studies are carried out with the parameters listed in Table IV. The rectifier is compared in terms of input current, power factor and THD value with different conditions (different load and input voltage).

The magnitudes of voltage fluctuations do not usually exceed $10 \%$ of the nominal supply voltage. For more reliable results, the supply voltage $\pm 10 \%$ variation conditions are taken into consideration. Three case examples were simulated to show the effects on the grid. The worst case situation can be described when the supply voltage is higher than 10 percent because rectifier shows poor PF characteristics and high harmonic contents for some of the reasons will be mentioned.

Table 4 Parameters Used for Simulation

\begin{tabular}{|c|c|}
\hline Rectifier output power (ma & $50 \mathrm{kVA}$ \\
\hline \multicolumn{2}{|c|}{ Line-to-line voltage in RMS } \\
\hline Case $1 \quad 418 \mathrm{~V}$ & $418 V(380 V+10 \%)$ \\
\hline Case 2 & $380 \mathrm{~V}$ \\
\hline Case 3 & $342 \mathrm{~V}(380 \mathrm{~V}-10 \%)$ \\
\hline Frequency & $50 \mathrm{~Hz}$ \\
\hline \multicolumn{2}{|c|}{$\mathrm{Ls}=2 \mathrm{uH}, \mathrm{Lm}=1 \mathrm{H}$} \\
\hline Resistance of Transform & $\mathrm{Rp}=1 \mathrm{~m} \Omega \mathrm{Rs}=63 \mathrm{u} \Omega$ \\
\hline DC output voltage & $122 \mathrm{~V}$ \\
\hline DC output current (max.) & $400 A$ \\
\hline Filter cut-off frequency & $600 \mathrm{~Hz}$ \\
\hline
\end{tabular}

In the full load $400 \mathrm{~A}$ and the input voltage is $418 \mathrm{~V}$, the graphs of the state are shown in Fig 3. (a) shows the waveform of utility line current and (b) shows its FFT components, the harmonic magnitudes versus input current in per unit system, (c) shows the primary currents IpD, IpY and their sum IpDY, (d) shows the current of each filter group.

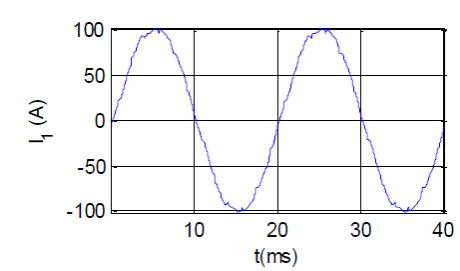

(a)

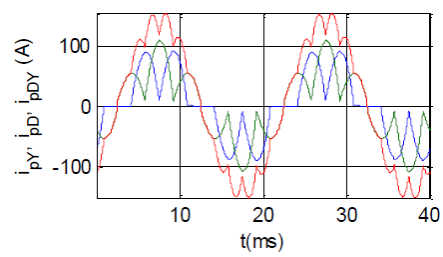

(c)

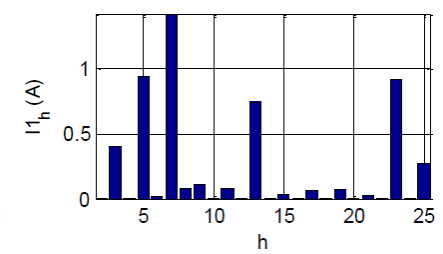

(b)

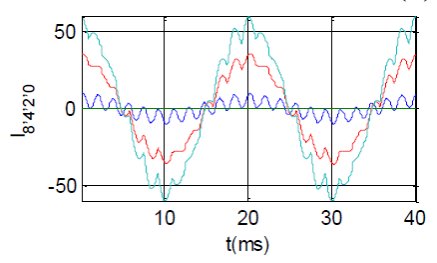

(d)

Figure 3 Rectifier currents for Case 1. (a) Input current waveform. (b) Harmonic contents of the input current. (c) $\mathrm{I}_{\mathrm{p}_{-} \mathrm{Y}}, \mathrm{I}_{\mathrm{p}_{-} \mathrm{D}}$ and $\mathrm{I}_{\mathrm{p}_{-} \mathrm{DY}}(\mathrm{d})$ Filter currents

$\mathrm{I}_{1}, \mathrm{I}_{\mathrm{h}}, \mathrm{I}_{\mathrm{pD}}, \mathrm{I}_{\mathrm{pY}}, \mathrm{I}_{\mathrm{pDY}}, \mathrm{I}_{8}, \mathrm{I}_{4}, \mathrm{I}_{2}, \mathrm{I}_{0}$ parameters were obtained in the simulation results. $\mathrm{I}_{8}, \mathrm{I}_{4}, \mathrm{I}_{2}$, and $\mathrm{I}_{0}$ are the currents of each filter groups, respectively. The primary currents of each transformer are shown as $\mathrm{I}_{\mathrm{pD}}$ and $\mathrm{I}_{\mathrm{pY}}$. $\mathrm{I}_{\mathrm{pDY}}$ is the sum of $\mathrm{I}_{\mathrm{pD}}$ and $\mathrm{I}_{\mathrm{pY}}$ currents. Also, these imply the currents before the grid and filter. 
The I1 is obtained by the filter operation represents the changing of current drawn from the network. $\mathrm{I}_{1 \mathrm{~h}}$ shows the harmonic amplitudes of the current $\mathrm{I}_{1}$.

It is clear from this figure that the supply current comes near to the sine-wave with $3.19 \%$ THD and 0.98 PF.

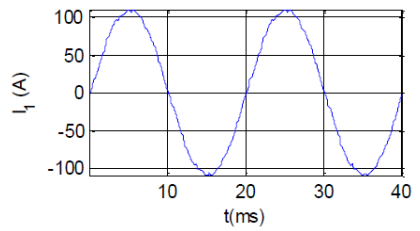

(a)

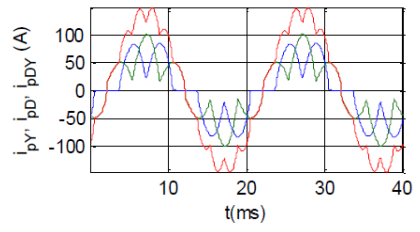

(c)

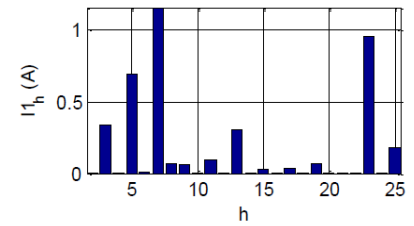

(b)

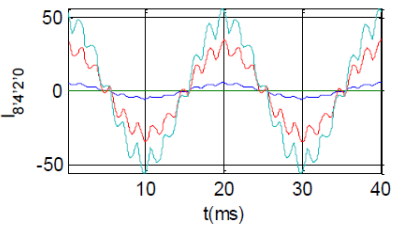

(d)

Figure 4 Rectifier currents for Case 2. (a) Input current waveform. (b) Harmonic contents of input current. (c) $I_{p_{-} Y}, I_{p_{-} D}$ and $I_{p_{-} D Y}(d)$ Filter currents

Fig. 4 shows the supply current waveform and its FFT components with respect to the input voltage 380 $\mathrm{V}$. The firing angle $\alpha$ plays an important role in THD of the line current. For a constant DC output voltage, when the input voltage increases, the firing angle $\alpha$ increases. In case 2 , it is clear that the THD value is lower than the case 1 because of its input voltage value. It is clear from this figure that the supply current comes very near to the sine-wave with $2.46 \%$ THD and $0.99 \mathrm{PF}$.

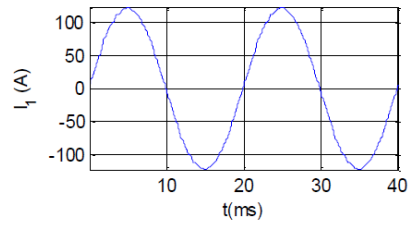

(a)

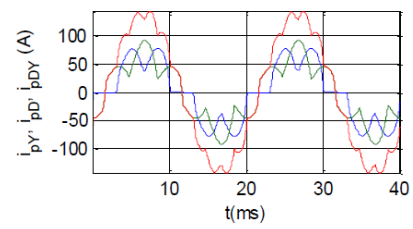

(c)

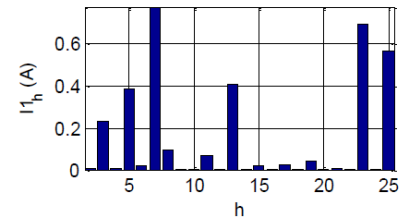

(b)

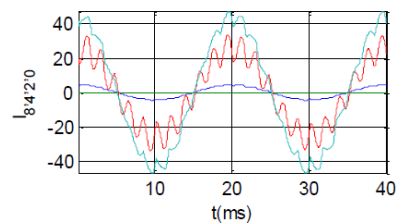

(d)

Figure 5 Rectifier currents for Case 3. (a) Input current waveform. (b) Harmonic contents of the input current. (c) $\mathrm{I}_{\mathrm{p}_{-} \mathrm{Y}}, \mathrm{I}_{\mathrm{p}_{-} \mathrm{D}}$ and $\mathrm{I}_{\mathrm{p}_{-} \mathrm{DY}}(\mathrm{d})$ Filter currents

Fig. 5 depicts the simulation results of the proposed system with $342 \mathrm{~V}$ input voltage. In case 3 , the rectifiers operate the lowest input voltage and the lowest firing angle $\alpha$. Therefore, Fig. 5 reveals that the best THD value of the line current. It is clear from this figure that the supply current comes very near to the sine-wave with $1.69 \%$ THD and $0.99 \mathrm{PF}$. 


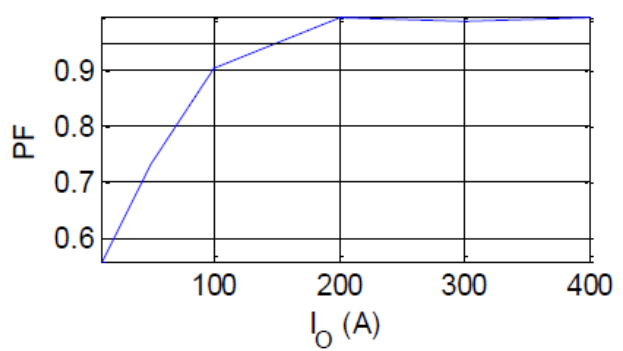

Figure 6 The relation between PF and load

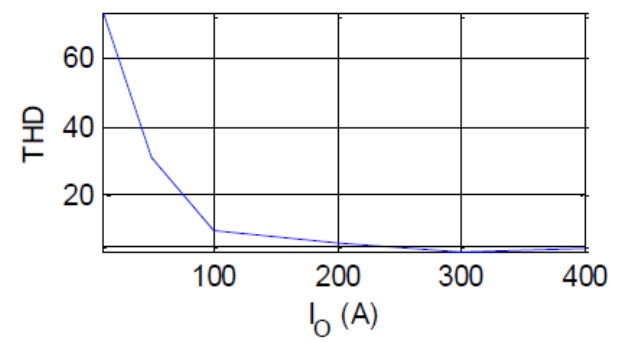

Figure 7 The relation between THD and load

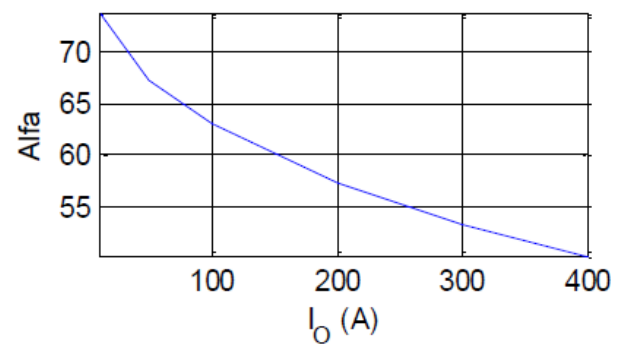

Figure 8 The relation between firing angle and load

In order to comply with the standards, it is necessary to identify the worst-case harmonic distortion. Therefore, the worst case situation has been determined the supply voltage is $418 \mathrm{~V}(380 \mathrm{~V}+10 \%)$. The proposed system has been examined different load conditions with the input voltage $418 \mathrm{~V}$. The system operates $400 \mathrm{~A}$ in the full load. Fig. 6 show variation the power factor under the load from $0 \%$ to $100 \%$. As can be seen from Fig. 6, the proposed system ensure that the PF value is greater than 0.9 loaded from $25 \%$ to $\% 100$. Fig. 7 show variation the THD under the load from $0 \%$ to $100 \%$. As can be understood from Fig. 7, the proposed system meets the harmonic limits from $25 \%$ to $\% 100$ load.

As shown in Fig. 8, when the load decreases from $\% 100$ to $\% 0$, the firing angle $\alpha$ increases. In the industrial applications, rectifiers are desired to limit the firing angle from $20^{\circ}$ to $60^{\circ}$. Because commutation problems occur above the firing angle $60^{\circ}$. As can be seen from Fig. 8, the proposed system does not exceed the 60 up to $20 \%$ load.

\section{Conclusion}

The lower pulse rectifiers suffer from the problem of current harmonics in high power applications. Poor $\mathrm{PF}$ and high input harmonics are the most important drawbacks. In order to meet international standards, it has been observed that a conventional 48 pulse rectifier is needed. However, these problems are solved by a structure of 12 pulse rectifiers with an adaptive filter group. The advantages of these solutions have been highlighted in terms of power quality and THDi value. To demonstrate the performance of the proposed system, three case examples were simulated in PSIM. The low harmonics current, high PF and high efficiency of the proposed system are probably its most attractive aspects. The THDi value of the developed system is smaller than the IEEE limits and the power factor is greater than 0.95 at $100 \%$ load. 
As a main conclusion of this paper, a thyristor rectifier conforming to international standards and having high energy quality has been developed.

\section{References}

A. M. Trzynadlowski, "Power electronic converters and systems" The Institution of Engineering and Technology 2016.

IEEE Recommended Practices and Requirements for Harmonic Control in Electrical Power Systems, IEEE Standard 519, 1992.

Alexa, D., Sirbu, A., Dobrea, D. M., “An Analysis of Three-Phase Rectifiers with Near-Sinusoidal Input Currents", Industrial Electronics, IEEE Transactions on, Volume 51, Issue 4, Aug. 2004, Page(s):884-891, 2004.

Hacer Ucgun \& Yasemin Onal., "A Comparative Analysis of Control Algorithms Used for Shunt Active Power Filter with PSIM”, International Journal of Scientific and Technological Research ISSN 2422-8702 (Online) Vol 4, No.8, 2018.

B. Sanzhong and M. L. Srdjan, "New Method to Achieve AC Harmonic Elimination and Energy Storage Integration for 12-Pulse Diode Rectifiers," IEEE Transactions on Industrial Electronics, vol. 60, pp. 2547-2554, 2013.

S. Srdic and M. Nedeljkovic, "Predictive Fast DSP-Based Current Controller for Thyristor Converters," Industrial Electronics, IEEE Transactions on, vol. 58, pp. 3349-3358, 2011. 